\title{
Our Shamanistic Past: The Korean Government, Shamans and Shamanism
}

BOUDEWIJN WALRAVEN

The form of popular religion usually referred to as shamanism ${ }^{1}$ has been a matter of concern to Korean authorities for many centuries. This concern has been mainly negative, but there have been fluctuations and shifts in the perception of shamanism; particularly in recent years a more positive attitude has been noticeable. Shamanism has become a cultural symbol associated with the roots of the Korean people, with some of the most important elements of the Korean national identity, and it is now frequently suggested that it is the underlying force (chorryŏk) that, against great odds, has made possible ethnic survival for thousands of years. In this paper we will trace the development of government attitudes to the complex of phenomena which is today labelled shamanism ("syamanijŭm," or alternatively musok or mugyo in modern Korean; in the first half of this century it was more commonly referred to as mishin, "superstition"). The emerging picture will show how this change in attitude was a combination of outside influences and developments within society.

\section{The Pre-Modern Period}

In the early Chosŏn period, in the fifteenth and sixteenth centuries, a redefinition of ritual to conform to Neo-Confucian standards formed a major part of a far-reaching transformation of Korean society. ${ }^{2}$ First and foremost affected were the yangban, the members of the hereditary status group qualified to fill official posts in the government bureaucracy. For them, adherence to Confucian 
standards of civilized behaviour - which implied a rejection of reliance on shamans - became a prerequisite for maintaining social status. But the general reorganization of rituals also had consequences for the lower orders. The government attempted to bring various forms of local worship under the control of its bureaucracy, at the same time discouraging autonomous forms of worship by the population. In this way, central government made its presence felt wherever it sent its officials, even to the lowest administrative level, that of the county (kun, a Great County, or hyŏn, a Small County). Special rituals, called yŏje, performed in times when epidemics or famine raged served to express the paternal concern of the ruler for the people, implicitly reminding them of their dependence on the center of power. ${ }^{3}$

All this meant that little or no scope was allowed the shamans, the mudang, in officially approved ritual. The Confucian concept of civilization was not compatible with shamanic forms of worship. Gradually mudang lost the role they had played in certain forms of ritual performed by the government (rain prayers, for instance), and other cults in which they were active, too, became the object of repression. A famous instance of the latter is found in the biography (haengjang) of an eighteenth-century magistrate of Cheju Island, Yi Hyŏng-sang (1653-1733), which recounts how Yi systematically propagated Confucian values on the island by repairing Confucian shrines, promoting education, and forbidding such things as mixed bathing, excessive nudity of women and marriage between people of the same surname or with mutual mourning obligations. ${ }^{4}$ This biography also contains the following passage, with reference to a meeting between $\mathrm{Yi}$ and representatives of the population: ${ }^{5}$

When His Excellency spoke in detail about the evil of excessive sacrifices in places where these were not needed [at all], everyone said: "How would we dare to disobey Your Excellency's command?" After they had left, they spontaneously passed on the message to each other and burned down 129 shrines together with two Buddhist temples and threw close to a thousand Buddha images into the sea. The altar tables of the mudang were burned and the mudang went back to agriculture. 
When Yi Hyŏng-sang left the island, the same source says, the population in four places erected stèles in praise of his virtue. In this biography, an almost colonial image is presented of the representative of a superior civilization who, by dint of this superiority, effortlessly manages to convince and convert the backward natives. That in reality the islanders were not all that happy to relinquish their gods and that at least a certain degree of coercion was involved, may be inferred from the situation of Cheju Island in the twentieth century, where local shrines of a nature that would certainly be judged unorthodox by Neo-Confucians can still be found in great abundance. Apparently, the effect of Yi's campaign was not lasting. It is not surprising, therefore, that a recently recorded narrative shaman song from the island, in its rendering of the exploits of Yi Hyŏng-sang, reverses the final outcome: in the end the magistrate has to recognize the power of the deities he has rejected. ${ }^{6}$

There is no reason to accept the image of paternal benevolence presented in works like Yi Hyŏng-sang's biography at face value. No doubt, to introduce "civilization" involved a certain measure of repression or institutionalized violence. Nevertheless, Confucian civilization possessed a certain persuasive power of its own certainly not made less attractive by the fact that it was the cultural capital of the dominant elite - and thus had the potential to make converts. In fact, this is what happened: Confucian values filtered down to social milieus far removed, both physically and figuratively, from the center of power. In remote areas like Cheju Island this took place relatively late and to a relatively minor degree, but near the end of the Chosonn period even rural society had been Confucianized to a considerable extent. The mudang no longer found their patrons among those who took part in public life, the men, but primarily among women, who for a variety of reasons were less easily convinced by Confucian propaganda against shamans. ${ }^{7}$ Men who (publicly) relied on mudang belonged to the lowest classes in society. One group was the fishermen, the danger and risk of whose occupation were in inverse proportion to their social prestige.

The result of all this was that in the nineteenth century no one in a position of power and authority, no one with claims to a proper 
education, would want or dare to raise his voice in favour of the shamans. On the contrary, anyone who wanted to assert his own superiority could do so by speaking against them. In educated circles the evil ways of the mudang were not a subject of discussion: this was considered to be self-evident. The only point of debate was the degree of vigour with which they should be repressed. Some advocated total eradication of this evil, others were content to leave the mudang in peace as long as they limited their activities to areas that were marginal in the eyes of the elite. ${ }^{8}$

\section{The Transitional Years}

When Korea was opened up to foreign influence little changed in this respect. As the central ideology of power, Confucianism quickly lost in influence but the representatives of modernization and the western missionaries criticized the mudang no less fiercely than the Confucian scholars had done. Shamanism (a term that was first used in this period, with pejorative intentions, by western missionaries) also was the bete noire of the new forces that emerged in Korean society around this time: the incipient Christian churches with their modern schools and the political and social reformers, such as those who met in the Independence Club, and who tried to mobilize public opinion through the new medium of the newspaper. In their zeal against practices they deemed superstitious, progressive journalists often surpassed the authorities. They urged the police not to flag in their persecution of the mudang and incited citizens to join in the battle against superstition. An editorial in the English language paper The Independent of December 1, 1896 first attacked acupuncture and then directed its arrows at the mudang:

Another equally outrageous custom in Korea is that when a person is sick, either a blind man or a sorceress is called in to beat drums, sing songs and wail out prayers to drive away the evil spirit. After the prayer is over the sorceresses make the patients eat the food that has been offered, thinking that it will act as medicine to them. Recently a case came to our notice that a dysenteric patient died immediately after eating 
raw turnips and some boiled rice which were given to him by a sorceress after the usual ceremony of worshipping the evil spirit. We would have wondered at his recovery under such treatment. We hope the new Chief of Police will keep up his former record by prohibiting mutangs in the city who have become very numerous since the last Chief of Police succeeded the present occupant in June.

A few months earlier the same paper reported:

Yi Eung Du of Mo Ha-Kwan, after reading the statements in the Independent concerning the deleterious effect of devil worship, tore down a temple inside of his compound and burned up the images voluntarily. We do not care to boast of what good the paper does in unknown ways, but occasionally such facts come to our notice and we rejoice at them. ${ }^{9}$

In Chayujong (The Bell of Freedom) by Yi Hae-cho, one of the stories in the new style (shin-sosoll) which began to be published after 1906 (often in the newspapers), employing a mudang is without further ado condemned as typical of depraved and ill-mannered women. ${ }^{10}$ In this climate, it is hardly surprising that certain efforts by mudang to improve their social standing ended in dismal failure. ${ }^{11}$ The authorities and political and religious organizations of various kinds were as one in their scorn for the shamans.

With the annexation of Korea by Japan in 1910 the situation changed somewhat. The vernacular newspapers which had so fiercely attacked the mudang were suspended and vigorous Korean organizations could no longer operate. The new rulers did not regard the popular cults of the shamans as of any use - they were more inclined to promote Buddhism as a possible linking factor between Japan and Korea ${ }^{12}$ - and rather considered them a hindrance to the development of the peninsula. Yet they lacked the Confucian animus against the mudang and, on the whole, probably were a little more ready to let things be, as long as that did not interfere with their plans and projects. But all in all little changed for the mudang. In the 1920s, however, a new tendency became perceptible, which, in the long run, would turn out to be of considerable importance. 


\section{Nationalistic Reappraisal of Shamanism}

The colonial oppression of the Koreans by the Japanese stimulated some intellectuals to think about their national identity and to take a new look at their own history and culture. In this process, shamanism began to appear in a different light. The very first trace of this process may perhaps already be detected in the 1880s, when the recent opening of Korea and the appearance of foreign powers on the scene encouraged a nativistic reaction, which, inter alia, found expression in the Tonghak movement. A brief, illustrated description of shamanic ritual in classical Chinese, which most likely can be dated 1885 and is called Mudang naeryouk (History of the Mudang), points out several abuses in contemporary mudang rituals but, on the other hand, displays a more positive attitude, for it links the mudang to the mythical founder of Korea, Tan'gun (who in the past century has been the focus of many nationalistic movements).$^{13}$ The author deplores some of the aspects of shamanic ritual in his day, but apparently regards these as abuses that have crept in in the course of time. Originally, he suggests, the rituals of the mudang were valid.

However, as this may be, in the 1920s a number of publications testify to a new interest in shamanism. Son Chin-t'ae was the first scholar to pay serious attention to shaman songs, which he started to collect and eventually published in his Chösen shinka ihen (Collection of Remnants of the Divine Songs of Korea), while Ch'oe Nam-sŏn and Yi Nŭng-hwa published studies on shamanism in the periodical Kyemyŏng (Dawn) in 1927. Of these Yi Nŭng-hwa wrote a descriptive, very factual study, whereas $\mathrm{Ch}^{\prime}$ oe Nam-sŏn was more apt to theorize, and integrated his ideas concerning shamanism into articles he wrote on other subjects. He also wrote at length on the history of ancient Korea and identified Tan'gun, the founder of the state of Old Chosorn, as a shaman ruler. As the figure of Tan'gun was a highly valued national symbol, this implied a view of shamanism that was quite different from that of the old scholarofficials. In a way, by taking shamanism seriously Ch'oe Nam-sŏn followed the example of Western studies of shamanism and folklore, with which he was well acquainted. The general thrust and perspective of his work, however, were nationalistic, as he tried to 
strengthen Korean self-awareness by an amazingly wide range of writings on Korea's cultural heritage. It is a curious fact that Ch'oe's interest in shamanism was also to a certain degree stimulated by the research of Korean customs and beliefs commissioned by the Japanese Government General. This was undertaken with the thought that it might reveal similarities between Japanese and Korean culture, which could facilitate assimilation of Koreans to Japanese culture. Ch'oe's study of the same subject matter had a very different purpose. He intended to prove that Koreans were historically not as intimately related to the Japanese as the latter would have it. In this respect, the concept of shamanism, suggesting links of Korea with continental Northeast Asia and Siberia rather than with the Japanese islands, was most useful, particularly since Japanese scholars at that time denied the existence of shamanism in Japan. ${ }^{14}$ Thus, it was in reaction to the Japanese occupation that in this period a more positive attitude toward shamanism began to emerge, in uneasy coexistence with the older negative view, which continued to reject shamanism as foolish superstition.

Certain literary works of the 1930s, which employ elements from popular religion as symbols of Korean identity, equally indicate that shamanism and related phenomena were viewed in a different way. Famous is the story "Munyŏdo" (Portrait of a Shaman) by Kim Tongni, first published in 1936, which treats the conflict between a mudang mother and her Christian son. Much later Kim himself explained why he introduced shamanism (mugyo) as a theme in his work:

Inasmuch as shamanism was the primitive religion of the Korean people, I took the view that the characteristic view of the divine, and of the life in this world and the hereafter of the Korean people would be contained in it. As it was the period when the Japanese Government General ruled us, I wanted to preserve the characteristic spirit of Korea for ever, even though it was only by giving it a place in a work of literature. ${ }^{15}$

As a second reason Kim Tongni mentioned that he was looking for a new creative energy in religion and considered the more established religions as spent forces in this respect. It seems that one 
of the attractions of shamanism for him was its perceived primitivism. This is much emphasized in the story, which in spite of the interests it betrays in shamanism, does not show a great understanding of the actual nature of the rituals and life of the mudang. In a way, the source of energy Kim looked for in shamanism was something which European artists in the twentieth century found in forms of so-called primitive art, in African sculpture for instance, in other words in cultures which were very different from their own. To Kim Tongni, shamanism was in a sense something exotic, far removed from his own life and that of most of his readers, while, paradoxically, at the same time he chose it as a symbol of the essence of his own culture. This paradox, however, I believe to be essential to the attraction and the effectiveness of the symbol. The mechanism at work here may be observed frequently when national symbols are created. Often these are not taken from the troubled immediate present, but from the more or less distant past, which more easily lends itself to the projection of ideas and ideals. In his literary creations, Kim Tongni found an appropriate symbol for the "spirit of Korea" in the living past of shamanism. ${ }^{16}$

One year after Munyŏdo, in 1937, the story Sadang (later retitled Sŏnangdang, "The Village Shrine") by Chŏng Pisŏk was published in one of the Korean newspapers, the Chosorn ilbo. The shrine in the title of this story, devoted to a shamanistic tutelary deity, is its central symbol and stands for the deepest layers of Korean identity. In an article in which he argued for the value of Chŏng Pisŏk's story as a form of indirect, cultural resistance against colonial oppression, David Mesler judged that, "the symbols which could be identified as native to the soil became powerful tools in the fight to stay alive as a separate ethnic family." ${ }^{17}$ Popular religion was a source of such symbols.

\section{After Liberation}

Liberation from colonial rule in 1945 did not bring much relief to the mudang. ${ }^{18}$ Prejudice against them remained very strong and the police often interfered with their rituals. The activities of the mudang were by many regarded as something shameful, to be hidden from 
outsiders. ${ }^{19}$ A foreigner asking directions to a mudang's house would often be told that in this neighbourhood there was no one like that. In this context a curious organization developed, the Korean Association for Victory over Communism and Respect for Belief (Taehan sünggong kyŏngshin hyŏphoe), founded in 1970. However strange the name may sound, in fact the combination of anticommunism and respect for popular beliefs had a logic of its own. Anti-communism was the purpose which could justify the existence of the organization to the authorities and induce them to show a certain leniency toward the mudang. The organization, of course, also could serve as a means of control over a group that was otherwise hard to suppress. The history of this association since its inception reflects changing political realities and changing attitudes to shamanism in Korean society. Whereas in the beginning one of its most important aims, apart from anti-communist activities, was to protect its members against police harassment, with the passing of time it has increasingly occupied itself with the preservation of shamanism and at present even organizes courses for newly initiated mudang to learn how to perform the rituals properly. ${ }^{20}$

Before the situation took a turn for the better, however, shamans in rural areas had to cope with attempts to eradicate superstition through the New Community Movement (Saemaŭl undong) initiated by the government in 1971, in order to accelerate the development of rural communities and narrow the gap between city and country - and, one may add, to retain the rural vote. The movement intended to promote self-help, but in fact the villagers were expected to help themselves in conformity with quite specific government directives. The modernization propagated by the movement was to be rational, scientific and economic. ${ }^{21}$ Many old customs, not only shamanic rituals but also Confucian traditions, were thought to be incompatible with this modernization, as they were deemed irrational, and diverted much-needed cash to unproductive ends. It should be noted that, as in the Chosŏn period, the suppression of certain local customs was not merely coercive. It was presented as part of what one might call a civilization campaign, a campaign to educate rural Koreans so that they would exchange their traditional habits and values for more modern and superior standards; all this, of course, for their own benefit. ${ }^{22}$ 
Rather than the rituals for individual households, those for village communities suffered from the New Village Movement. In many places, the changsŭng, totempole-like guardians, which stood near the village entrance and were the focus of communal rites, were pulled down, too. But a change was on the way. While in one village the elders were debating if they should follow government instructions and remove the changsüng - some feared supernatural afflictions should they do $\mathrm{so}^{23}$ - another government instruction arrived, this time from the Ministry of Culture and Education, with the request to report on local folk customs. This the villagers took as a hint to leave the changsüng unmolested. ${ }^{24}$

The request from the Ministry was part of a drive to preserve and promote traditional Korean culture which, no less than the New Community Movement, characterized the policies of President Park Chung-hee, who wanted to boost the nation's confidence by an awareness of Korea's cultural heritage. ${ }^{25}$ For this purpose, it was necessary to study things that were typically Korean and make a concerted effort to save Korea's own spiritual culture. While this was the original intention, it is doubtful if the government planners had a clear idea of what exactly should be preserved and what, eventually, would be the direction the campaign would take. This depended not so much on the government bureaucracy, as on the academic specialists, who acted as advisers in these matters.

\section{Scholars and Shamanism}

Between Liberation and the 1970's the idea that shamanism was not only worth studying, but also formed an important part of Korean culture, sporadically met with in pre-Liberation days, had gradually grown more common in academic circles. This happened first of all among folklorists, musicologists and students of Korean literature. Kim Tong-uk, an eminent scholar of Korean literature, for instance, in his book Han'guk kayo-ŭi yŏn'gu (Studies of Korean Songs), which appeared in 1961, time and again emphasized that many poetic genres of traditional Korean literature had shamanistic roots: in the songs of the mudang. But the concept of the importance of shamanism in Korean culture was not confined to the categories of 
scholars mentioned above. Similar ideas one finds, for example, in the work of a major law scholar, Yu Ki-ch'ón, a professor at the prestigious Law School of Seoul National University. He was of the opinion that one could not understand Korean culture without taking shamanism into account. He discerned a remarkable influence of shamanism on the Korean language in general and on the law-related use of language in particular. ${ }^{26}$

The "shamanism" such scholars write about is not necessarily the same phenomenon as the beliefs and rituals of the mudang; frequently it has but little to do with the reality of the life of Korean shamans, and should be considered rather an invention, or a projection of certain ideas of these authors. This tendency to improvise freely on the theme of shamanism is manifested to an extreme degree in an essay written by another law scholar, Hahm Pyong-choon. His opinions are all the more interesting as he moved in government circles as much as in academia, serving as a special assistant for political affairs to Park Chung-Hee and as Korean Ambassador to Washington. ${ }^{27}$ Acknowledging that the world view he discusses cannot be called "purely" shamanistic, Hahm stretches the meaning of the term shamanism to surprising length. In his usage, almost anything that might be considered traditionally Korean is styled "shamanistic," including matters one might prefer to call Confucian or that are common to East-Asian culture in general. At times, that what is called "shamanistic" is almost universally applicable. The sentence "shamanistic folklore abounds with stories in which various species of beasts reciprocate human kindness" would be just as true if the adjective "shamanistic" was omitted. ${ }^{28}$ Much of the description of shamanism is in the negative and the underlying pattern is always that it is not like modern Western thinking. Hahm also does not shy away from generalization and reification. "Shamanism has failed to be impressed by the intrusion of sexuality into the parent-child relationship," is a fairly representative example. ${ }^{29}$

In history, both of the academic and the more popular variety, it has become received wisdom to state that the original religion of the oldest Koreans was shamanism. According to Hahm Pyong-choon it was "Korea's earliest and only indigenous religion." ${ }^{130}$ It is, however, rarely discussed what the exact meaning of this labelling 
is and the related assumption that ancient kings themselves were shamans. One may wonder what ancient kings and modern mudang, the latter of low status and mostly women, have in common. Is it possession, ecstasy? Old sources do not really enlighten us in regard to this; the information they provide is too fragmentary to draw farreaching conclusions. The fact, for instance, that in one source the title of the ruler is glossed with a character $m u$ (Chinese, $w u$ ) for which the conventional translation is "shaman", of course, tempts us to assume a connection with shamanism, but in concrete terms it does not mean much. ${ }^{31}$ One may, therefore, question whether it makes sense to attach the label "shamanism" to ancient Korean religion. Nevertheless, one cannot overlook the consequences of this labelling. Not only does it give the mudang an impressive historical pedigree in a culture where historical roots are of the greatest importance, it also makes them bearers of true Korean culture at a time when nationalist fervour puts a supreme value on "our things" (uri kŏt). ${ }^{32}$

\section{Governmental Protection of Shamanism}

The fact that in academic circles shamanism became salonfähig in the 1960s and 1970s influenced government programmes for the preservation of cultural property. It is highly unlikely that government bureaucrats originally had mudang in mind when they devised measures to preserve culture, ${ }^{33}$ but in spite of this, at present several mudang rituals are officially designated as Intangible Cultural Assets (muhyŏng munhwajae) and the mudang who perform them receive government stipends as Human Cultural Assets or "keepers" (poyuja) of these rituals. One university professor who has acted as adviser in these matters told me with great satisfaction that in the early days of the Asset system they had tricked the authorities into protecting certain East Coast mudang by persuading them to preserve the Tano Festival in Kangnŭng - one of the festivals for local guardian deities, such as were traditionally held in many communities - in which the mudang play an indispensable role. At that time it was still impossible to protect the mudang directly. Such ploys were necessary in the beginning, but as time 
went by it became more widely accepted to regard mudang as bearers of traditional culture. At present almost everyone accepts as a matter of course that certain mudang are appointed guardians of Korea's cultural heritage.

It would be naive to assume that the positive government attitude implied in the inclusion of mudang in the cultural asset system merely protects them, that it just allows them to pursue their usual occupation without harassment from the police, for instance. The consequences of the system for a shamanic ritual from Chindo called ssikkim kut have been studied in detail by Keith Howard, who first of all notes that this ritual, when on the verge of extinction, was revived with the express purpose of receiving recognition as an Intangible Cultural Asset. ${ }^{34}$ This affected the form. The performers used texts for the songs, for example, they thought would go down well with the folklorists who were to judge whether the ssikkim kut was worth preserving. Even if a mudang does not change her rituals to be accepted by the Asset selection masters, the system may lead to change. A mudang who has become a Human Cultural Asset becomes a model to others, which may lead to the disappearance of alternative styles of performing the same ritual.

The case of the ssikkim kut is not unique as an example of mudang ritual revived as a consequence of governmental initiative. In the same way the festival for a famous Chosŏn-period general, Nam I (1441-1468), worshipped as a local guardian deity in Seoul, was given new life in 1983, after having been discontinued in 1971. Half of the expenses were provided by the (government-sponsored) Korean Culture and Arts Foundation and the Seoul City government - the remainder being paid by the participants. Its resurrection was justified with the argument that it would provide the citizens of Seoul with opportunities for recreation and impart a sense of history. ${ }^{35}$ A "modern" addition to the festival, geared to this purpose, was a parade re-enacting General Nam's campaign against the Jurchen. However, a substantial part of the proceedings was in the hands of mudang, who even played a more important role than before, because they were called upon to perform the ritual every year, not once in three years as had been the custom. ${ }^{36}$ It should be noted that among the inhabitants of the neighbourhood, beliefs remained alive that had far more to do with the original purpose of 
the festival than with the new one as given by the authorities. People hoped that the festival would bring them luck and noted that the person who had impersonated Nam I in the parade had done very well in his business, in spite of a general economic slump. ${ }^{37}$ Apparently, the way local participants, whom one would be tempted to call the "true believers," viewed the festival did not coincide with the perspective of the authorities. The irony of the case is that the fact the festival was revived and celebrated again was due to the officials and not to the believers.

The government's change of attitude also manifests itself in the way Korea is presented to the world. With government approval and support shaman teams travel all over the world to "perform" for international audiences. Clearly, what they display on foreign stages, without the setting that gives the ritual its original purpose, is their ability as musicians, singers, dancers or actors. A normal ritual derives its sense from the interaction between the patrons for whose benefit it is performed and the mudang. In the last analysis, it can be argued, it is intended to achieve a spiritual or psychological transformation in the patrons for whom the mudang work. This aspect of ritual is, however, not what the government particularly cares for. The interest is in form rather than function. This was highly evident when in November 1991 the Ministry of Culture had a complete ritual filmed of one of the most famous shamans of modern Korea, Yi Chisan, who for that purpose had returned from his present place of residence, Honolulu. Instead of filming a ritual commissioned by actual patrons in natural surroundings, the decision was taken to use as the setting a house in the Folk Village - a kind of open air museum, not uninteresting but sterile - and to have members of a dilettante group interested in shaman ritual, a singer of folk songs and her disciples, act as patrons. Needless to say, everyone was dressed with impeccable "traditionality."

In government-sponsored presentations of shamanism, in whatever form, the religious aspect of ritual is neglected, if not consciously played down. With shamanism as a living belief the authorities are uncomfortable, certainly where Korea's image abroad is concerned. Already in the late 1970s, the Ministry of Information made a documentary film exclusively devoted to mudang rituals, to 
be shown in foreign countries. This film, which includes a section about the ssikkim kut, ends with a sequence of shots of highrise buildings, computer rooms and neat, modern offices, while the commentary suggests that modern Koreans are merely nostalgically attached to shamanism as part of the old way of life. A booklet issued by the Korean Overseas Information Service in 1985 equally hints that shamanism is essentially a thing of the past: "Animism persisted in coloring the Korean versions of other world religions as they reached the peninsula, and survives today in the continuing reliance by simple rural people [emphasis added, BW] on the ceremonies conducted by shamans, or mudang..." ${ }^{38}$ If this were true, mudang rituals would decline as rapidly as the rural population, which is dwindling fast and nowadays makes up less than a fourth of the population (against 53.7 percent in 1966). In fact, mudang are very active in the metropolis of Seoul and their total number in the whole of the country is estimated to be about 60,000 (in a population of about 43.5 million). ${ }^{39}$ Contrary to what one might think, shaman rituals nowadays are largely an urban phenomenon.

In spite of the fact that the government is not keen to encourage the religious dimension of shamanism, it may unwittingly be doing so, as has already been suggested when the festival for Nam I was discussed. Moreover, the new respectability given to the mudang by the fact that they are now eligible to become officially designated and proud preservers of cultural assets, and by their regular appearances in the media in this capacity, seems to have changed the attitude of the public. In recent years, mudang have noted an unusual number of new candidates who aspire to become shamans. The cause of this has not yet been thoroughly examined, but quite likely it is because the traditional social stigma that rested on the occupation of mudang is getting somewhat less and some of them, the "superstar shamans" 40 (and it is with these that the general public is most often confronted), have even acquired a kind of glamour. ${ }^{41}$ If this is the correct explanation, the government, by contributing to an improvement of the social status of the mudang, unwittingly promotes that aspect of shamanism of which it is most critical. 


\section{Shamanism and Political Protest}

The government fosters selected elements of shamanism, but the evaluation of shamanism as something truly Korean, which is at the basis of this, is quite general. It is not surprising, therefore, to find it also in the fiercest opponents of the government, the students and dissidents, who use "shamanistic" symbols to good effect to dramatize their demonstrations and formulate their criticism. Their way of dealing with shamanism may be called more creative than that of the government, which is above all concerned with preservation, and - in the eyes of the dissidents - fossilizes the spirit of folk culture. ${ }^{42}$ The dissidents consciously give new meanings to old symbols. The old changsŭng, for instance, traditionally guardians of villages, have reappeared on the campus as guardians of democracy. The dissidents are not unlike the government, however, in that they keep a certain distance from the actual practices of the mudang, which they, too, tend to regard as backward. An example of this is found in the so-called Kut Movement (kut undong). Kut is the general term for a shamanic ritual, but also has a wider meaning, something like "spectacle," and has also been used for certain festive communal events having certain elements in common with shamanic ritual performed by others than mudang. Stressing this latter fact allows the adherents of this movement on the one hand to make use of "shamanistic" symbolism and on the other hand to keep the mudang at arm's length. ${ }^{43}$ They are not interested in mere preservation of the rituals of so-called authentic mudang. The introductory text on the cover of a book that propounds the ideas of this movement first seems to attack the negative view of shamanism common in the first half of this century, and then states the intention of the authors to reform and develop the kut into something quite unlike mudang ritual: "This book firmly rejects the current imperialistic view which looks down on the kut of our people as superstition or wild ravings ... and advocates the total rehabilitation of our $k u t$ as a way of struggle to break the shackles of the oppression of our nation and our people. ${ }^{\text {"44 }}$ All the same, the shamanistic roots of kut are recognized and, not unexpectedly, criticism of present practices of the mudang goes together with a positive view of the role of the mudang in the past, the time before 
government repression during the Chosŏn period led to their alleged degeneration. ${ }^{45}$

\section{Conclusion}

To conclude I will briefly summarize the above, drawing the various strands together. In the pre-modern period, the religious rituals of the mudang were subject to official disapproval and the educated deemed them fit for women and country bumpkins only. This did not immediately change after Korea was opened up in 1876, and to a certain extent the old negative view of the mudang still lives on today. But contacts and clashes with the outside world fostered a nationalistic reaction, an attempt to find one's identity in a changed world, and this started off interest in what was perceived as Korea's oldest faith, shamanism. This was not necessarily an interest in the mudang and their rituals as they were actually performed. Nationalistic scholars and intellectuals reconstructed or invented a form of shamanism that fitted their needs and could bolster national pride. Perhaps the use of the term shamanism should be reserved for this reconstruction as opposed to actual shamanic ritual and belief.

The more positive evaluation of shamanism, a true volte-face when the harsh prejudice against mudang prevalent among the educated in the first half of the twentieth century is considered, slowly but steadily gained in influence. Today the idea that the core of Korean identity can be found in shamanism is widespread. To illustrate how pervasive this idea has become, one need only mention the fact that a Korean Christian has made a study of the rituals of the mudang in order to find ways to indigenize the rituals of his own church. $^{46}$ Thus, when the government looked for means to strengthen national morale by convincing Koreans that they were heirs to a great historical and cultural legacy, it was not altogether unexpected that shamanism would be presented as part of the glorious past. At the very same time, though, the mudang were subjected to a campaign against superstition. This is less paradoxical than it may seem. The government used and uses shamanism as an abstraction, by no means congruent with the reality of what mudang 
and their patrons actually do, in order to boost self-confidence; it has no commitment whatsoever to the substance of shamanic beliefs. The mudang fare scarcely better with the critics of the government, who in their own way manipulate a related construct to further their cause. Both government and dissidents essentially regard the mudang as figures of the past. An unimpassioned observer cannot, but note that this is far from true. The mudang are undoubtedly affected by changes in society and they adapt to these changes in all kinds of ways, but by sheer numbers may claim a place in modern Korea. One may question whether their traditional customs are alive and well, but they themselves are far from extinct and, in fact, develop new traditions, fitting the society in which they live. Modern mudang themselves quite often accept their new image as keepers of ancient Korean culture, and actively propagate it. A striking example is furnished by a male shaman, Chŏng Kang- $u$, who recently published a three-volume novel about the life of a mudang, with the stated intent of preserving "our things." ${ }^{177}$ Earlier Chŏng had already distinguished himself by organizing shaman rituals which aimed to dissolve the resentments caused by certain events in national history, such as the 1894 Tonghak Rebellion, thus concerning himself with matters quite different from the domestic and village community problems on which the more traditional mudang rituals are focussed. The majority of mudang, unlike him, do not receive the limelight of public attention, but they, too, adapt in such a way that they may retain a function in modern society. ${ }^{48}$ It would be highly surprising were they not to survive, in one form our another, well into the twenty-first century. In fact, they may very well outlive the present popularity of "shamanism."

Dr. Boudewijn Walraven is Associate Professor at the Centre for Japanese and Korean Studies, University of Leiden. 


\section{NOTES}

1 This term is widely used for the religion of the mudang, but there is an on-going debate whether this can be justified on theoretical or practical grounds.

2 Han U-gŭn, "Chosŏn wangjo ch'ogie issŏsŏ-ŭi yugyo inyŏm-ŭi shilch'ŏn-gwa shinang.chonggyo saje munje-rŭl chungshim-ŭro-" "Unorthodox Religions" and the Realization of Confucian Ideals in the Early Chosŏn Period - with emphasis on the problem of worship), Han'guk saron, Vol. 3 (1976), pp. 147-228; Martina Deuchler, The Confucian Transformation of Korea (Cambridge, Mass.: Harvard University Press, 1992).

3 Boudewijn Walraven, "Confucians and Restless Spirits," in Leonard Blussé and Harriet T. Zurndorfer, eds., Conflict and Accommodation in Early Modern East-Asia (Leiden: E.J. Brill, 1993), pp. 71-93.

4 Yi Hyŏng-sang, Pyŏngwa chip (kugyŏk-) (Collected Works of Pyŏngwa, in Korean translation), Vol. 3 (Sŏngnam: Han'guk chŏngshin munhwa yŏn'guwŏn, 1990), pp. 229230.

5 Yi, Pyŏngwa chip, Vol. 3, p. 230.

6 Hyŏn Yong-chun, Chejudo musok charyo sajŏn (Cyclopaedia of Materials Concerning the Shamanism of Cheju Island) (Seoul: Sin'gu munhwasa, 1980), pp. 811-815.

7 This was a matter of education and exposure to Confucian values, as well as of their particular requirements and needs. In a forthcoming paper I will discuss this problem in greater detail.

8 This is not to say that the yangban never had recourse to the services of the mudang in private; some of them certainly had.

9 The Independent, August 22, 1896.

$10 \mathrm{Yi}$ Hae-cho, Chayujong (The Bell of Freedom), in the series Shinsosŏl.pŏnan (yŏk) sosŏl, Vol. 4 (Seoul: Asea munhwasa, 1978), p. 3; the original edition was published in 1910 .
11 Boudewijn Walraven, "Shamans and Popular Religion Around 1900," paper for workshop "Korean Religions" (Copenhagen, June 1992).

12 Wi Jo Kang, Religion and Politics in Korea Under the Japanese Rule (Lewiston/Queenston: Edwin Mellen Press, 1987), pp. 45-47.

13 Boudewijn Walraven, "Interpretations and Reinterpretations of Popular Religion in the Last Decades of the Chosŏn Dynasty," paper for the workshop "Korean Shamanism Today" (London, December 1992).

14 Roger J. Janelli, "The Origins of Korean Folklore Scholarship," Joumal of American Folklore, Vol. 99 (1986), pp. 31-34; Michael E. Robinson, Cultural Nationalism in Colonial Korea, 1920-1925 (Seattle and London: University of Washington Press, 1988), pp. 80-81.

15 Postscriptum to Kim Tongni, Ǔlhwa, 2nd. ed. (Seoul: Munhak sasang ch'ulp'anbu, 1981), p. 353. In Ülhwa, Kim Tongni transformed the short story Munyodo into a voluminous novel. This rewriting of Munyodo shows that he was not unaware of the academic work done on Korean shamanism in the meantime, yet his view of shamanism remains highly romantic and is far from a realistic depiction of the life and activities of the mudang.

16 See Yi T'ae-tong, "Syamanijŭm-gwa shilchon-jŏk minjok munhak" (Shamanism and existentialist national literature), in Yi T'ae-tong, ed., Kim Tongni (Seoul: Pyŏkho, 1993), pp. 226-260. Of course, Kim's treatment of shamanism is not exclusively motivated by nationalistic feelings. Thus, according to $\mathrm{Yi}, \mathrm{Kim}$ looks in the primitive beliefs of shamanism for a world in which man's reason and spirit are still one; p. 230.

17 David P. Mesler, "Korean Literature of Resistance: A Case for Chŏng Pisǒk," in Andrew C. Nahm, ed., Korea Under Japanese Colonial Rule: Studies 
of the Policy and Techniques of Japanese Colonialism (Kalamazoo: Center for Korean Studies, Western Michigan University, 1973), p. 230.

18 What follows applies to the Republic of Korea, "South Korea", only. In North Korea, the mudang seem to have disappeared entirely.

19 Park Ki-hyuk and Sidney D. Gamble, The Changing Korean Village (Seoul: RAS, 1975), pp. 98, 136.

20 Alexandre Guillemoz, "Qu'apprennent les naerim mudang de Seoul?," paper for the Workshop "Korean Shamanism Today" (London, December 1992).

21 Ch'oe Chu-ch'ŏl, Saemaŭl undong-ŭi iron-gwa ch'orrhak (Theory and Philosophy of the New Community Movement), 2nd ed. (Seoul: Chimmundang, 1978), p. 166.

22 As often happens in such cases, the understanding on the part of the campaigners of the lives of those who should be converted was incomplete and biased; see Vincent S. R. Brandt, "Rural Development and the New Community Movement in South Korea," Korean Studies Forum, No. 1 (Autumn-Winter 19761977), p. 35.

23 The belief that those who harm changsüng will receive supernatural punishment is widely attested. It is found in a rather frivolous form in the p'ansori libretto Pyŏn Kangsoe ka. Kim Tu-ha, Pŏksu-wa changsŭng (Guardian Posts and Images) (Seoul: Chimmundang: 1990), p. 731, with regard to the changsüng of the village under discussion here, records the story that a young man who had urinated against the changsung was afflicted by a boil on his penis, and only recovered when he had shown proper respect through sacrifice and prayer.

24 Lee Kyung-hee, "Tutelary Gods of Happiness," article in a series entitled "Koreana," in Korea News Review, March 6, 1993, pp. 24-25.

25 Already in 1972, one year after the initiation of the New Community Movement, the Ministry of Home
Affairs issued instructions warning against the destruction of cultural property due to excessive zeal in the implementation of this movement; Kim Tu-ha, Pǒksu-wa changsüng, $\mathrm{p}$. 23.

26 Ch'oe Chong-ko, Han'guk pŏpsasang $s a$ (History of Korean Legal Thought) (Seoul: Seoul taehakkyo ch'ulp'anbu, 1989), pp. 357-359.

$27 \mathrm{Hahm}$, "Shamanism and the Korean World-View, Family Life-cycle, Society and Social Life," in Richard W. Guisso and Chai-shin $\mathrm{Yu}$, eds. Shamanism: The Spirit World of Korea (Berkeley: Asian Humanities Press, 1988), pp. 60-97.

$28 \mathrm{Hahm}$, "Shamanism and the Korean World-View," p. 73.

29 Ibid., p. 66.

30 Ibid., p. 60.

31 Of course, there is, in spite of this, a voluminous literature arguing for the "shamanistic" nature of various ancient rulers; of this the writings which try to prove that Tan-gun himself was a shaman are a good example.

32 See Kim Tu-ha, Pŏksu-wa changsŭng, pp. 21-22, where it is argued that the changsung should be protected because they are "our things."

33 The Cultural Asset system of Japan, which served as a model for the Korean one, does not cover folk arts, let alone shamans.

34 Keith Howard, Bands, Songs, and Shamanistic Rituals: Folk Music in Korean Society (Seoul: RAS, 1989), Chapter 9. Also see Howard, "Namdo Tül Norae: Ritual and the Intangible Cultural Asset System," Journal of Ritual Studies, Vol. 3, No. 2 (Summer, 1989), pp. 203-216.

35 Korea Newsreview, December 3, 1983, p. 25.

36 Seoul minsok taegwan: min'gan shinang $p^{\prime}$ youn (Survey of the Folklore of Seoul: Popular Beliefs), Seoul t’ŭkpyŏlshi munhwajae wiwŏnhoe, comp. (Seoul: 1990), p. 281; the duration of the ritual was reduced, however, in conformity with the 
general trend in mudang rituals; ibid. p. 285.

37 Mun Yŏng-ok, "Nam I changgun taeje" (The Great Festival of General Nam I), Han'gug-üi minsok, Vol. 3 (March, 1986), pp. 257-262.

38 Facts About Korea, produced by $\mathrm{H}$. Edward Kim (Seoul: Hollym Corporation, 1985), p. 236.

39 Alexandre Guillemoz, "Seoul, la veuve et la mudang: les transformations d'un chamanisme urbain," Diogène, No. 158 (Avril/Juin 1992), pp. 104-115; Kim Yŏl-kyu a.o., Han'guk munhwa-ŭi ppuri (The Roots of Korean Culture), 2nd ed. (Seoul: Ilchogak, 1990), p. 181.

40 Choi Chungmoo, "Superstar Shamans in Korea: Nami, Ch'ae and Oksun," in. Ruth-Inge Heinze, ed., Shamans in the Twentieth Century (New York: Irvington Publishers, 1991), pp. 51-61.

41 Guillemoz, "Seoul, la veuve et la mudang," pp. 109-110, 112-114.
42 Minjok-kwa kut (The People and Kut), comp. by Minjokkut-hoe (Seoul: Hangminsa, 1987), p. 191; Choi, "Superstar Shamans," pp. 5455.

43 Chu Kang-hyŏn, Kus-ŭi sahoesa (Social History of the Kut) (Seoul: Ungjin ch'ulp'ansa, 1992), p. 18.

44 Cover of Minjok-kwa kut.

$45 \mathrm{Chu}$, Kus-üi sahoesa, pp. 22-28.

46 Il-Young Park, Minjung, Schamanismus und Inkulturation: schamanistische Religiosität und Christliche Orthopraxis in Korea, Dissertation Freiburg, Switzerland (Seoul: 1988).

47 Chŏng Kang-u, Mudang, Vol. 1 (Seoul: Hyŏnamsa, 1993), p. 8.

48 In a paper for the workshop "Korean Shamanism Today" (London, December 1992) Laurel Kendall has drawn attention to such adaptations, among which she particularly noted the trend to follow the increasingly capitalistic values of modem Korea. 